\title{
The prognostic roles of ALDHI isoenzymes in gastric cancer
}

This article was published in the following Dove Press journal:

OncoTargets and Therapy

7 June 2016

Number of times this article has been viewed

\author{
Kai $\mathrm{Li}^{1,2}$ \\ Xiaoguang Guo ${ }^{3}$ \\ Ziwei Wang ${ }^{4}$ \\ Xiaofeng $\mathrm{Li}^{2}$ \\ Youquan $\mathrm{Bu}^{5}$ \\ Xuefeng Bai ${ }^{6}$ \\ Liansheng Zheng' \\ Ying Huang ${ }^{2}$ \\ 'Hepatobiliary Treatment Center, The \\ First Affiliated Hospital of Chongqing \\ Medical University, Chongqing, \\ ${ }^{2}$ Department of Medical Oncology, \\ ${ }^{3}$ Surgical Department, Baotou Cancer \\ Hospital, Baotou, Inner Mongolia, \\ ${ }^{4}$ Department of Gastrointestinal \\ Surgery, First Affiliated Hospital \\ of Chongqing Medical University, \\ Chongqing, ${ }^{5}$ Department of Biology, \\ Chongqing Medical University, \\ Chongqing, ${ }^{6}$ Department of Pathology, \\ ${ }^{7}$ Surgical Oncology, Baotou Cancer \\ Hospital, Baotou, Inner Mongolia, \\ People's Republic of China
}

\begin{abstract}
Increased aldehyde dehydrogenase 1 (ALDH1) activity has been determined to be present in the stem cells of several kinds of cancers including gastric cancer (GC). Nevertheless, which ones of ALDH1's isoenzymes are leading to ALDH1 activity remains elusive. In this study, we examined the prognostic value and hazard ratio (HR) of individual ALDH1 isoenzymes in patients with GC using "The Kaplan-Meier plotter" database. mRNA high expression level of $A L D H 1 A 1$ was not found to be significantly correlated with the overall survival (OS) of all patients with $\mathrm{GC}$ followed for 20 years, $\mathrm{HR}=0.86$ ( $95 \%$ confidence interval [CI]: 0.7-1.05), $P=0.13$. mRNA high expression level of $A L D H 1 A 2$ was also not significantly correlated with OS for all patients with GC, HR $=1.13$ (95\% CI: 0.91-1.41), $P=0.25$. mRNA high expression level of $A L D H 1 A 3$ was found to be significantly correlated with worsened OS in either intestinal-type patients, HR $=2.24$ (95\% CI: 1.44-3.49), $P=0.00026$, or diffuse-type patients, $\mathrm{HR}=1.91$ (95\% CI: 1.02-3.59), $P=0.04$. Interestingly, mRNA high expression level of $A L D H 1 B 1$ was found to be significantly correlated with better OS for all patients with GC, $\mathrm{HR}=0.66$ (95\% CI: $0.53-0.81), P=7.8 \mathrm{e}-05$, and mRNA high expression level of $A L D H 1 L 1$ was found to be significantly correlated with worsened OS for all patients with GC, HR $=1.23$ (95\% CI: $1-1.51), P=0.048$. Furthermore, our results also indicate that ALDH1A3 and ALDH1L1 are potential major contributors to the ALDH1 activity in GC, since mRNA high expression levels of $A L D H 1 A 3$ and $A L D H 1 L 1$ were found to be significantly correlated with worsened OS for all patients with GC. Based on our study, ALDH1A3 and ALDH1L1 are potential prognostic markers and therapeutic targets for patients with GC.
\end{abstract}

Keywords: KM plotter, cancer stem cell, ALDH1, hazard ratio, prognosis

\section{Introduction}

According to the World Health Organization, gastric cancer (GC), also known as stomach cancer, is the second most common cause of cancer-related death with 800,000 deaths caused by GC each year globally. ${ }^{1}$ Despite the progresses in early diagnosis and multimodal therapeutic modalities, at diagnosis, GC remains difficult to cure and prognosis remains poor for advanced disease in Western countries. ${ }^{2,3}$ Thus, in order to enhance the clinical consequence of patients with GC, exploration on the molecular mechanism of occurrence and progression of GC, as well as the development of prognostic biomarkers and drug targets, are still demanded and will assist to identify patients with high chances of $\mathrm{GC}$ recrudescence and deliver better prognosis and personalized treatments.

The aldehyde dehydrogenase 1 (ALDH1) family is detected at high levels in stem cells (SCs). ${ }^{4-6}$ ALDH1 activity has been discovered to be increased in multiple myeloma, myeloid leukemia, and a number of solid cancers. ${ }^{7-11}$ Wakamatsu et al ${ }^{12}$ first showed that cancer stem cell (CSC) markers, the level of ALDH1 positivity, are significantly higher in metastatic diffuse-type lymph node than in the primary tumor. 
Levi et $\mathrm{al}^{13}$ also observed that CSC markers, ALDH1, CD166, and LGR5, were detected in very low levels in normal human gastric mucosa, in contrast, significantly increased in gastric adenocarcinomas. Recently, Li et al reported that the expression of ALDH1A1 protein was significantly correlated with depth invasion, lymph node metastasis, stage of disease, as well as recurrence-free survival (RFS) and overall survival (OS). ${ }^{14}$ However, the prognostic role of most of the individual ALDH1 isoenzyme in GC has not been determined. In addition, which ones of ALDH1's isoenzymes are causing ALDH1 activity in GC remains elusive.

The "Kaplan-Meier plotter" (KM plotter) was developed from the database of Gene Expression Omnibus. ${ }^{15} \mathrm{KM}$ plotter can be utilized for the determination of prognostic role of individual genes in patients with cancer. ${ }^{16,17}$ Several genes so far have been reported using KM plotter in human breast cancer, ${ }^{18-26}$ as well as in ovarian and lung cancer. ${ }^{27}$ In the current study, we used KM plotter database and reported the prognostic role of individual ALDH1 isoenzymes in human patients with GC.

\section{Materials and methods}

We used an online database ${ }^{16}$ to determine the relevance of individual $A L D H 1$ members' mRNA expression to OS. Currently, breast cancer, ${ }^{16}$ lung cancer, ${ }^{28}$ ovarian cancer, ${ }^{29}$ and GC databases have been generated. All the cancer datasets were selected from Gene Expression Omnibus, ${ }^{15}$ Cancer Biomedical Informatics Grid, ${ }^{30}$ and The Cancer Genome Atlas. ${ }^{28,31}$ The database had a collection of clinical data including sex, perforation history, Lauren classification, differentiation, stage, HER2 status, and treatment. The patients with GC were followed up for 20 years. The database was finally created using gene expression data and survival information of 593 patients with GC. Five $A L D H 1$ isoenzymes (ALDH1A1, ALDH1A2, ALDH1A3, ALDH1B1, and $A L D H 1 L 1)$ were entered into the database (http://kmplot.

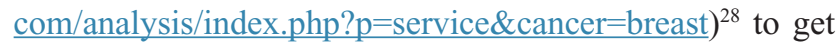
KM survival plots. The certain gene mRNA expression above or below the median separates the cases into high expression and low expression. Hazard ratio (HR) and log rank $P$ were determined and displayed.

\section{Results}

There are six sub-members in the ALDH1 family. We summarized their characteristics and listed them in Table 1. As $\mathrm{Wu}$ et $\mathrm{al}^{26}$ reported, only ALDH1L2 was not found in www.kmplot.com among all the six ALDH1 isoenzymes, probably due to its low expression.

We first checked the prognostic role of mRNA expression of $A L D H 1 A 1$ in the database. The valid gene Affymetrix ID is 212224_at (ALDH1A1). For all patients, survival curves are plotted $(n=593$; Figure 1A), for intestinal type $(\mathrm{n}=186$; Figure 1B), and for diffuse type $(\mathrm{n}=106$; Figure 1C). ALDH1A1 mRNA high expression was not found to be correlated with the OS for all patients with GC followed for 13 years, $\mathrm{HR}=0.86$ (95\% confidence interval $[\mathrm{CI}]: 0.7-1.05)$, $P=0.13$. ALDH1A1 mRNA high expression was also not found to be correlated with OS in intestinal-type patients, $\mathrm{HR}=0.72$ (95\% CI: 0.49-1.04), $P=0.078$, and in diffuse-type patients, $\mathrm{HR}=1.52$ (95\% CI: 0.87-2.66), $P=0.13$.

Then, we checked the prognostic role of mRNA expression of $A L D H 1 A 2$ in the database. The valid gene Affymetrix ID is: 207015_s_at (ALDH1A2). ALDH1A2 mRNA high expression was also not found to be correlated with OS for all patients with $\mathrm{GC}, \mathrm{HR}=1.13$ (95\% CI: 0.91-1.41), $P=0.25$ (Figure 2A). Interestingly, $A L D H 1 A 2 \mathrm{mRNA}$ high expression was found to be correlated with worsened OS in intestinal-type patients, $\mathrm{HR}=1.47$ (95\% CI: 0.99-2.19), $P=0.057$ (Figure 2B). In contrast, $A L D H 1 A 2$ mRNA high expression was found to

Table I Alternatively spliced variants and characterization of ALDHI isoenzymes

\begin{tabular}{|c|c|c|c|c|}
\hline Isoenzymes & Alternatively spliced variants & $\begin{array}{l}\text { Cellular } \\
\text { localization }\end{array}$ & Tissue distribution & Associated diseases \\
\hline ALDHIAI & ALDHIAI_v2 & Cytosol & $\begin{array}{l}\text { Brain, breast, Lung, } \\
\text { pancreas, kidney, liver, etc }\end{array}$ & Alcoholism \\
\hline ALDHIA2 & ALDHIA2 v2 ALDHIA2_v3 ALDHIA2_v4 & Cytosol & Kidney, liver, testis & Schizophrenia, spina bifida \\
\hline ALDHIA3 & ALDHIA3_v2 & Cytosol & $\begin{array}{l}\text { Breast, skeletal muscle, lung, } \\
\text { kidney, etc }\end{array}$ & $\begin{array}{l}\text { Autosomal recessive } \\
\text { anophthalmia/microphthalmia }\end{array}$ \\
\hline ALDHIBI & N/A & Mitochondria & $\begin{array}{l}\text { Liver, heart, kidney, brain, } \\
\text { prostate }\end{array}$ & Alcohol consumption and diabetes \\
\hline ALDHILI & N/A & Cytosol & Kidney, liver, skeletal muscle & Ischemic stroke \\
\hline ALDHIL2 & ALDHIL2 v2 ALDHIL2_v2 & Mitochondria & Brain, heart, pancreas & $\mathrm{N} / \mathrm{A}$ \\
\hline
\end{tabular}

Abbreviation: N/A, not applicable. 

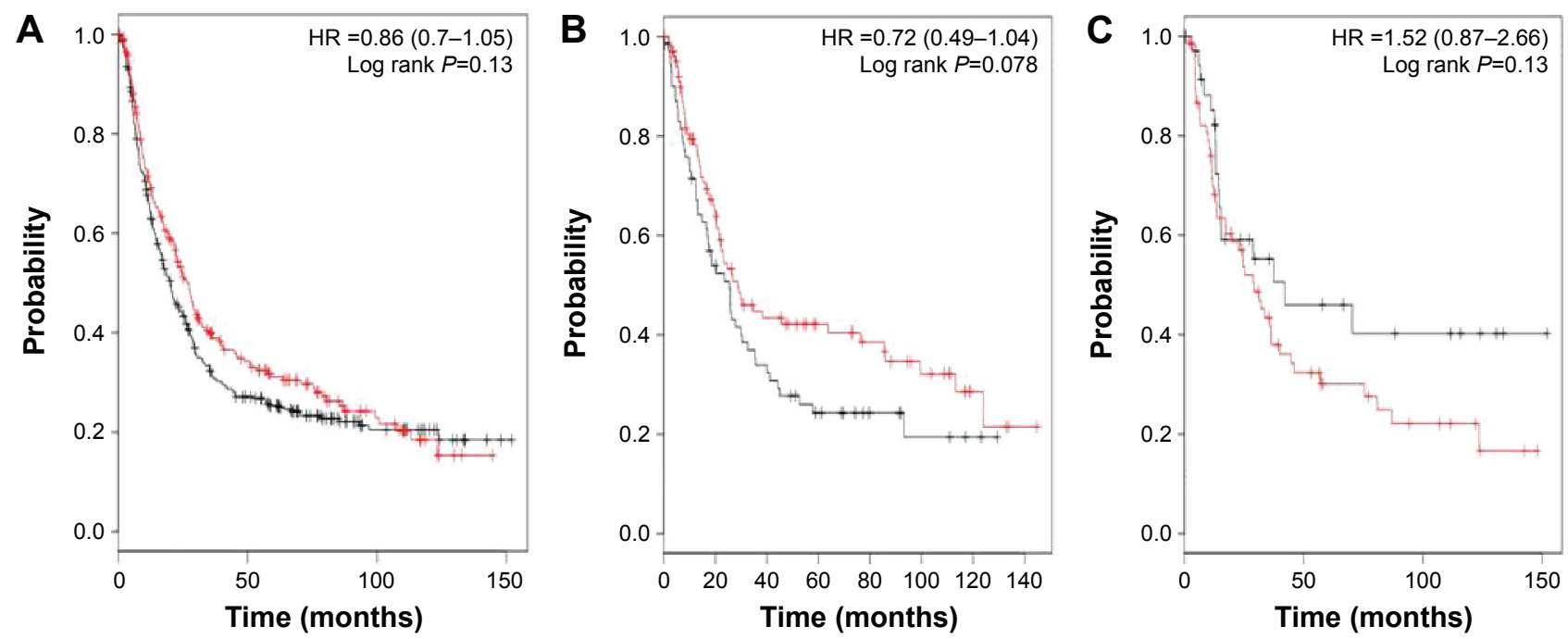

Number at risk

Number at risk

$\begin{array}{lllllllll}\text { Low } & 72 & 36 & 22 & 13 & 7 & 4 & 2 & 0\end{array}$

High $\begin{array}{llllllll}107 & 57 & 34 & 25 & 20 & 13 & 4 & 1\end{array}$

\section{Number at risk}

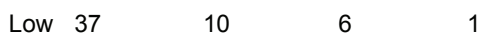

\section{Expression \\ - Low - High}

Figure I The prognostic value of ALDHIAI expression in the database.

Notes: The valid Affymetrix ID is 2I2224_at (ALDHIAI). (A) Survival curves are plotted for all patients ( $\mathrm{n}=593), \mathrm{HR}=0.86$ (95\% Cl: 0.7-I.05). (B) Survival curves are plotted for intestinal type $(n=186), H R=0.72(95 \%$ Cl: 0.49-1.04). (C) Survival curves are plotted for diffuse type $(n=106)$, HR =1.52 (95\% Cl: $0.87-2.66)$

Abbreviations: $\mathrm{HR}$, hazard ratio; $\mathrm{Cl}$, confidence interval.

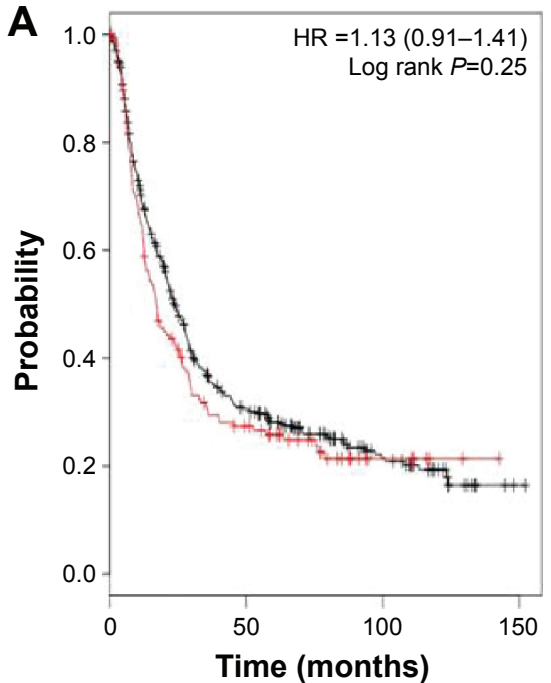

Number at risk

$\begin{array}{ccccc}\text { Low } & 435 & 104 & 33 & 1 \\ \text { High } & 158 & 36 & 8 & 0\end{array}$

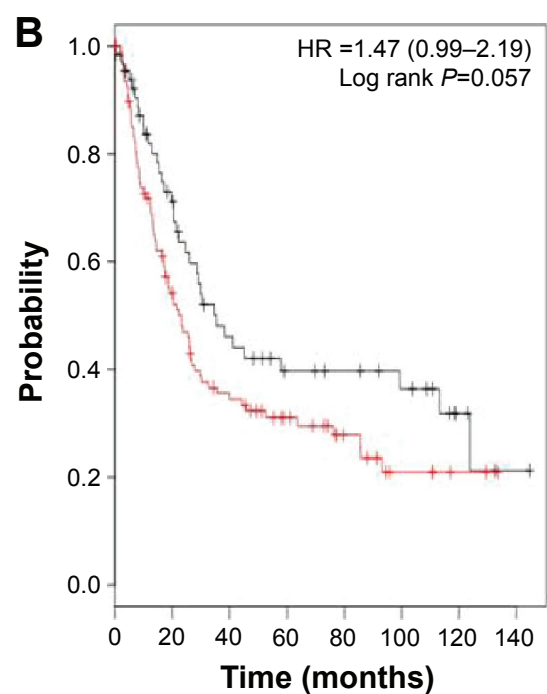

Number at risk

Low $\begin{array}{llllllll}67 & 39 & 23 & 16 & 14 & 11 & 4 & 1\end{array}$

High $\begin{array}{llllllll}112 & 54 & 33 & 22 & 13 & 6 & 2 & 0\end{array}$

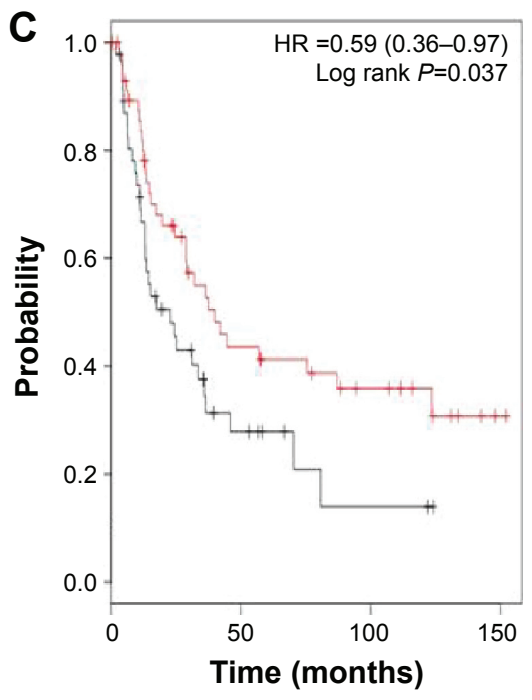

Number at risk

$\begin{array}{ccccc}\text { Low } & 47 & 8 & 2 & 0 \\ \text { High } & 59 & 19 & 11 & 1\end{array}$

Figure 2 The prognostic value of $A L D H I A 2$ expression in the database.

Notes: The valid gene Affymetrix ID is: 2070I5_s_at (ALDHIA2). (A) Survival curves are plotted for all patients ( $\mathrm{n}=593), \mathrm{HR}=\mathrm{I} . \mathrm{I} 3$ (95\% Cl: 0.9I-I.4I). (B) Survival curves are plotted for intestinal type ( $n=186), \mathrm{HR}=1.47$ (95\% Cl: 0.99-2.19). (C) Survival curves are plotted for diffuse type $(n=106)$, HR =0.59 (95\% Cl: $0.36-0.97)$.

Abbreviations: $\mathrm{HR}$, hazard ratio; $\mathrm{Cl}$, confidence interval. 
be correlated with better OS in diffuse-type patients, $\mathrm{HR}=0.59$ (95\% CI: 0.36-0.97), $P=0.037$ (Figure 2C).

Figure 3 shows the prognostic role of mRNA expression of $A L D H 1 A 3$ in the database. The valid gene Affymetrix ID is: 203180_at (ALDH1A3). The curves show that mRNA expression of $A L D H 1 A 3$ above or below the median do not separate the cases into significantly different prognostic groups in all patients with GC, HR $=1.19$ (95\% CI: $0.97-$ 1.46), $P=0.1$ (Figure 3A). However, $A L D H 1 A 3$ mRNA high expression was found to be significantly correlated with worsened OS either in intestinal-type patients, $\mathrm{HR}=2.24$ (95\% CI: 1.44-3.49), $P=0.00026$ (Figure 3B) or diffuse-type patients, $\mathrm{HR}=1.91$ (95\% CI: 1.02-3.59), $P=0.04$ (Figure 3C).

Figure 4 shows the prognostic role of mRNA expression of $A L D H 1 B 1$ in the database. The valid gene Affymetrix ID is: 209646_x_at $(A L D H 1 B 1)$. $A L D H 1 B 1 \mathrm{mRNA}$ high expression was found to be significantly correlated with better OS for all patients with $\mathrm{GC}, \mathrm{HR}=0.66$ (95\% CI: 0.53-0.81), $P=7.8 \mathrm{e}-05$ (Figure 4A). In addition, $A L D H 1 B 1 \mathrm{mRNA}$ high expression was also found to be correlated with better OS in intestinal-type patients, $\mathrm{HR}=0.7$ (95\% CI: 0.48-1.02), $P=0.06$ (Figure 4B), but not in diffuse-type patients, HR $=1.41(95 \%$ CI: 0.82-2.41), $P=0.21$ (Figure 4C).

Next, we examined the prognostic role of mRNA expression of ALDH1L1 in the database. The valid gene
Affymetrix ID is 205208_at (ALDH1L1). ALDH1L1 mRNA high expression was found to be significantly correlated with worsened OS for all patients with GC, HR $=1.23(95 \%$ CI: $1-1.51$ ), $P=0.048$ (Figure 5A). In addition, $A L D H 1 L 1$ mRNA high expression was also found to be correlated with worsened OS in intestinal-type patients, $\mathrm{HR}=1.44$ (95\% CI: 0.97-2.16), $P=0.072$ (Figure 5B). In contrast, ALDH1L1 mRNA high expression was found to be significantly correlated with better OS in diffuse-type patients, $\mathrm{HR}=0.5(95 \%$ CI: $0.31-0.83$ ), $P=0.0064$ (Figure 5C).

For further determination of the correlation of individual ALDH1 isoenzymes with other clinicopathological factors, we determined the correlation with pathological grades (Table 2), clinical grades (Table 3), HER2 status (Table 4), and different choices of treatment (Table 5) of patients with GC. From Table 2, it is found that, except for ALDH1A1, other ALDH1 isoenzymes' mRNA high expression is significantly associated with pathological grades. From Table 3, it is found that all the individuals with $A L D H 1$ mRNA high expression are significantly associated with clinical stages of patients with GC. From Table 4, it is found that ALDH1A1 and ALDH1A2 mRNA high expressions are only significantly associated with patients with HER2-negative GC. ALDH1B1 mRNA high expression is only associated with patients with

\section{A}

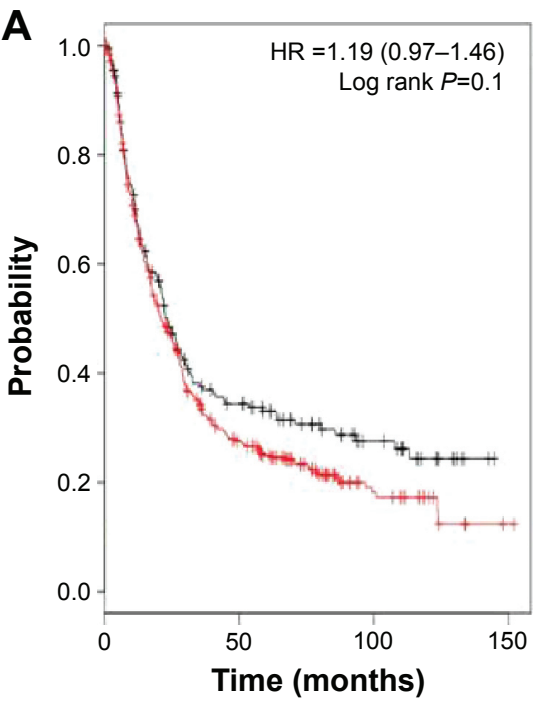

Number at risk

$\begin{array}{llll}\text { Low } 201 & 53 & 21 & 0 \\ \text { High } 392 & 87 & 20 & 1\end{array}$

B

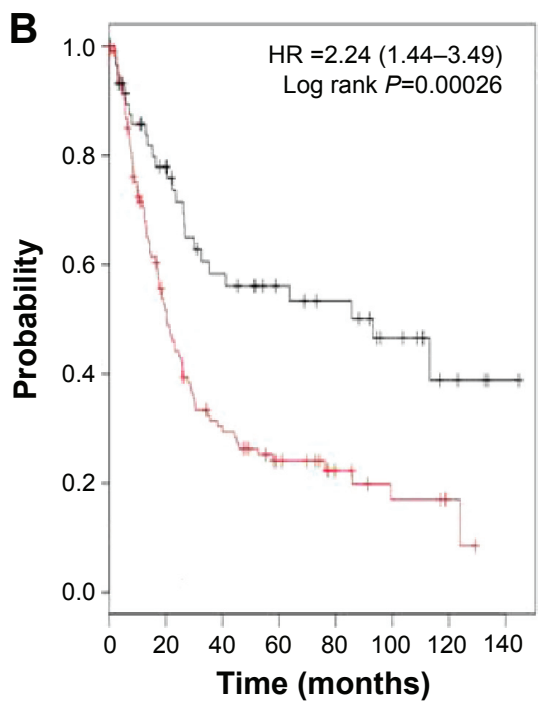

\section{Number at risk}

$\begin{array}{lllllllll}\text { Low } & 61 & 39 & 26 & 20 & 17 & 11 & 4 & 1\end{array}$

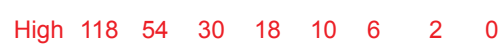

Expression

- Low - High

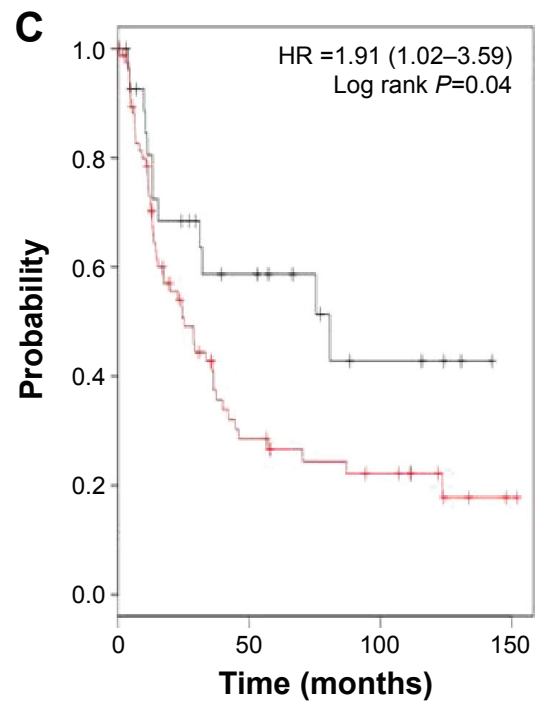

\section{Number at risk}

$\begin{array}{llll}\text { Low } 29 & 11 & 4 & 0 \\ \text { High } 77 & 16 & 9 & 1\end{array}$

Figure 3 The prognostic value of ALDHIA3 expression in the database.

Notes: The valid gene Affymetrix ID is: 203I80_at (ALDHIA3). (A) Survival curves are plotted for all patients ( $\mathrm{n}=593)$, $\mathrm{HR}=\mathrm{I} .19$ (95\% Cl: 0.97-I.46). (B) Survival curves are plotted for intestinal type ( $n=186)$, HR =2.24 (95\% Cl: I.44-3.49). (C) Survival curves are plotted for diffuse type ( $n=106)$, HR=1.9I (95\% Cl: I.02-3.59).

Abbreviations: $\mathrm{HR}$, hazard ratio; $\mathrm{Cl}$, confidence interval. 

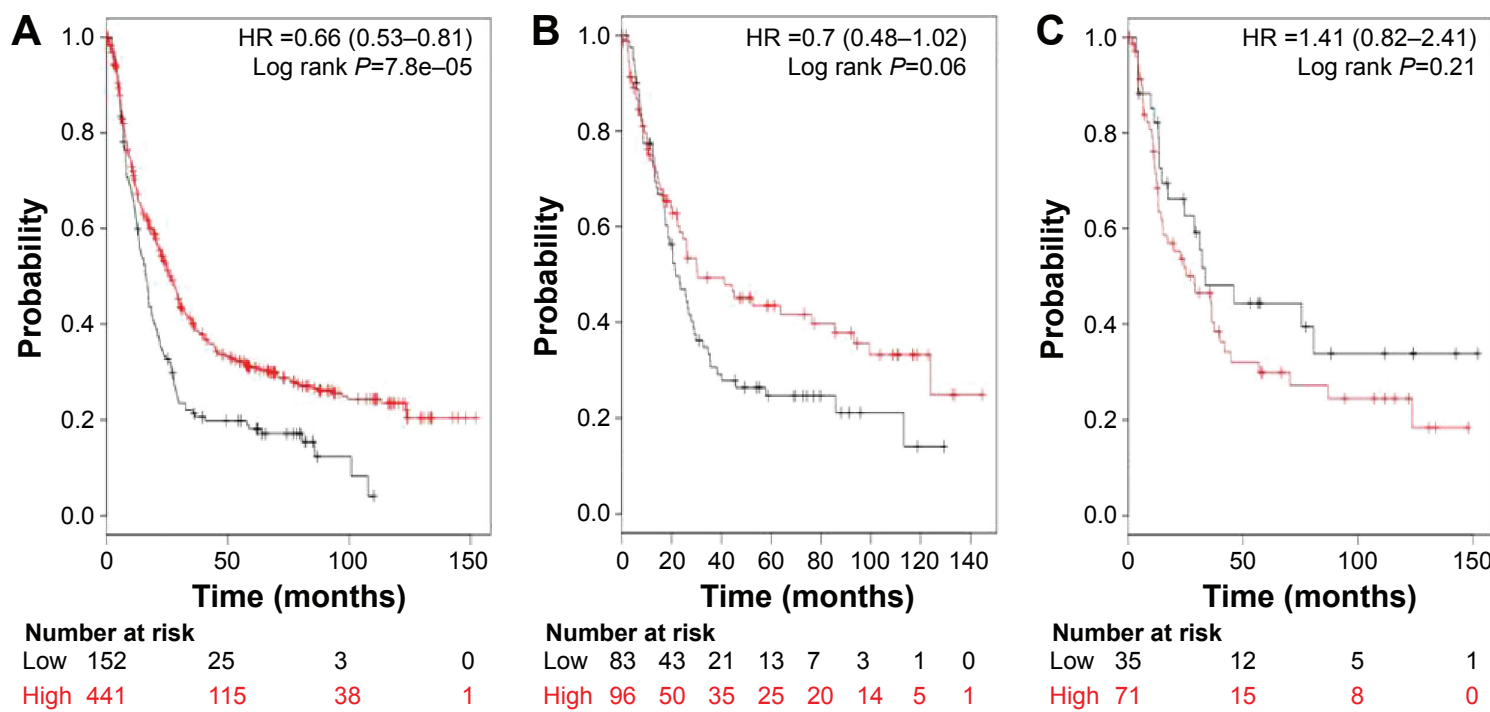

Expression

- Low - High

Figure 4 The prognostic value of $A L D H I B I$ expression in the database.

Notes: The valid gene Affymetrix ID is: 209646 × at (ALDHIBI). (A) Survival curves are plotted for all patients ( $\mathrm{n}=593)$, $\mathrm{HR}=0.66$ (95\% Cl: $0.53-0.8 I)$. (B) Survival curves are plotted for intestinal type $(n=\mid 86), H R=0.7(95 \% \mathrm{Cl}: 0.48-1.02)$. (C) Survival curves are plotted for diffuse type $(n=106)$, HR $=1.4 I(95 \% \mathrm{Cl}: 0.82-2.4 \mathrm{I})$.

Abbreviations: $\mathrm{HR}$, hazard ratio; $\mathrm{Cl}$, confidence interval.

HER2-positive GC. ALDH1A3 and ALDH1L1 mRNA high expressions are significantly associated with patients with HER2-negative and HER2-positive GC. From Table 5, it is found that with the exception of $A L D H 1 A 2$, other ALDH1 isoenzymes' mRNA high expression is significantly associated with different choice of treatment.

\section{Discussion}

Even though ALDH1A1 was first identified as a marker and a characteristic feature of primitive human hematopoietic stem cells isolated from bone marrow ${ }^{32}$ and of neural SCs, 33,34 studies have reported that other isoenzymes of ALDH1 (ie, ALDH1A2 and ALDH1A3) are also involved, because

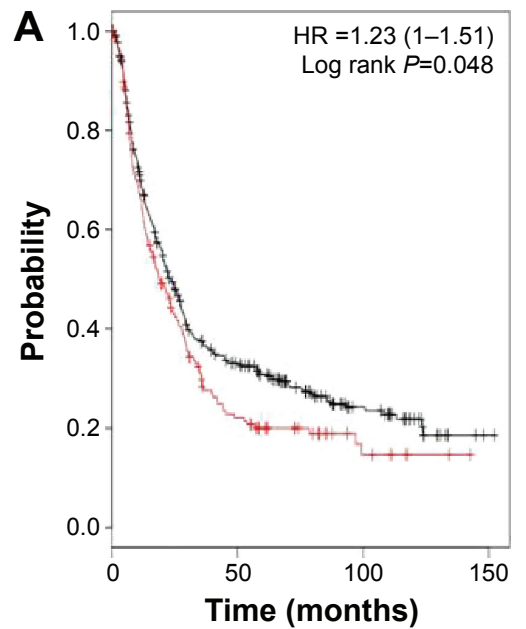

Number at risk

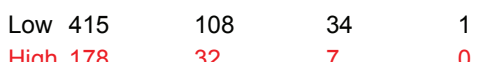

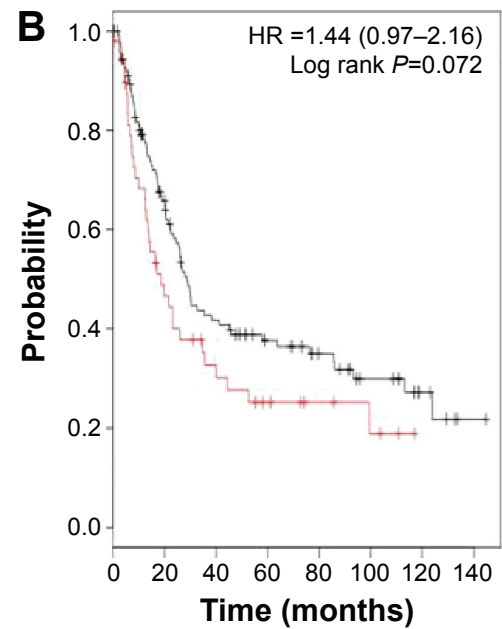

Number at risk

$\begin{array}{lllllllll}\text { Low } & 130 & 72 & 43 & 30 & 22 & 14 & 6 & 1\end{array}$

High $\begin{array}{llllllll}49 & 21 & 13 & 8 & 5 & 3 & 0 & 0\end{array}$

Expression

- Low - High

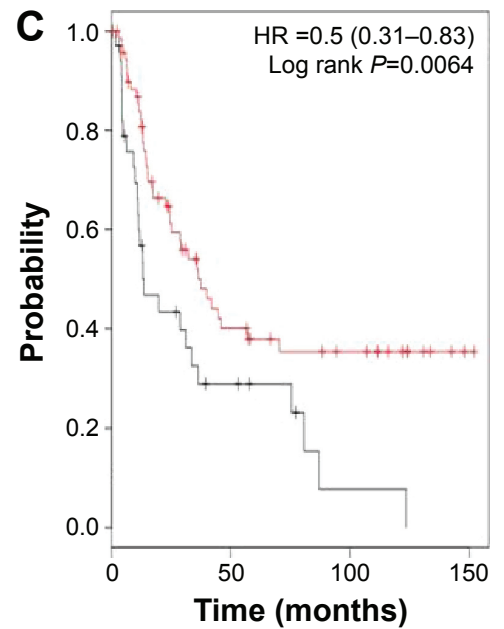

Number at risk

$\begin{array}{lllll}\text { Low } & 35 & 7 & 1 & 0 \\ \text { High } & 71 & 20 & 12 & 1\end{array}$

Figure 5 The prognostic value of ALDHILI expression in the database.

Notes: The valid gene Affymetrix ID is: 205208 at $(A L D H I L I)$. (A) Survival curves are plotted for all patients $(\mathrm{n}=593)$, $\mathrm{HR}=\mathrm{I} .23(95 \% \mathrm{Cl}$ : I-I.5I). (B) Survival curves are plotted for intestinal type $(n=186), \mathrm{HR}=1.44$ (95\% Cl: $0.97-2.16)$. (C) Survival curves are plotted for diffuse type $(n=106), \mathrm{HR}=0.5(95 \% \mathrm{Cl}: 0.3 \mathrm{I}-0.83)$.

Abbreviations: $\mathrm{HR}$, hazard ratio; $\mathrm{Cl}$, confidence interval. 
Table 2 Correlation of ALDHI isoenzyme mRNA high expression with pathological grades of patients with GC

\begin{tabular}{|c|c|c|c|c|}
\hline Isoenzymes & $\begin{array}{l}\text { Pathological } \\
\text { grades }\end{array}$ & Cases & HR (95\% Cl) & $P$-value \\
\hline \multirow[t]{3}{*}{ ALDHIAI } & I & 32 & $0.6(0.22-1.65)$ & 0.32 \\
\hline & II & 67 & 0.77 (0.4-I.49) & 0.43 \\
\hline & III & 165 & $1.49(1.0-2.23)$ & 0.51 \\
\hline \multirow[t]{3}{*}{ ALDHIA2 } & 1 & 32 & $1.53(0.63-3.69)$ & 0.34 \\
\hline & ॥ & 67 & $1.76(0.91-3.44)$ & 0.09 \\
\hline & III & 165 & $1.53(1.03-2.29)$ & 0.035 \\
\hline \multirow[t]{3}{*}{ ALDHIA3 } & 1 & 32 & $3.62(1.48-8.88)$ & 0.0027 \\
\hline & II & 67 & $2.5 \mathrm{I}(1.3-4.85)$ & 0.0048 \\
\hline & III & 165 & $1.8(1.2-2.7)$ & 0.0041 \\
\hline \multirow[t]{3}{*}{ ALDHIBI } & I & 32 & $0.37(0.15-0.92)$ & 0.026 \\
\hline & ॥ & 67 & $1.57(0.74-3.35)$ & 0.24 \\
\hline & III & 165 & $1.29(0.86-1.93)$ & 0.22 \\
\hline \multirow[t]{3}{*}{ ALDHILI } & I & 32 & $4.55(1.33-15.57)$ & 0.0082 \\
\hline & II & 67 & $2.19(0.94-5.09)$ & 0.064 \\
\hline & III & 165 & $0.6 \mathrm{I}(0.4-0.92)$ & 0.016 \\
\hline
\end{tabular}

Abbreviations: $\mathrm{GC}$, gastric cancer; $\mathrm{HR}$, hazard ratio; $\mathrm{Cl}$, confidence interval.

Aldh1A1 deficiency also did not affect Aldefluor staining of hematopoietic cells. ${ }^{35}$ It is believed that Aldh1 A1 is not a critical regulator of adult $\mathrm{SC}$ function or Aldefluor staining in mice, since Aldh1A1 deficiency did not affect the function of SCs from the adult central or peripheral nervous systems. Therefore, this heterogeneity indicates that the other isoforms of ALDH1 are responsible for Aldefluor activity in normal $\mathrm{SCs}$, as well as in CSCs. We hypothesis that individual isoenzymes of ALDH1 may also differently affect the outcome

Table 3 Correlation of ALDHI isoenzyme mRNA high expression with clinical stages of patients with GC

\begin{tabular}{|c|c|c|c|c|}
\hline Isoenzymes & Clinical stages & Cases & HR (95\% Cl) & $P$-value \\
\hline \multirow[t]{4}{*}{ ALDHIAI } & 1 & 67 & $0.6(0.17-2.15)$ & 0.43 \\
\hline & 2 & 140 & $2.35(1.12-4.96)$ & 0.021 \\
\hline & 3 & 305 & $0.63(0.46-0.86)$ & 0.0032 \\
\hline & 4 & 148 & $0.48(0.32-0.73)$ & 0.00043 \\
\hline \multirow[t]{4}{*}{ ALDHIA2 } & I & 67 & $1.95(0.44-8.65)$ & 0.37 \\
\hline & 2 & 140 & $0.7(0.38-1.29)$ & 0.24 \\
\hline & 3 & 305 & I.35 (I-I.83) & 0.047 \\
\hline & 4 & 148 & $1.36(0.92-1.99)$ & 0.12 \\
\hline \multirow[t]{4}{*}{ ALDHIA3 } & 1 & 67 & $4.66(0.61-35.4)$ & 0.1 \\
\hline & 2 & 140 & $2.92(1.6-5.35)$ & 0.00028 \\
\hline & 3 & 305 & $1.54(1.16-2.06)$ & 0.0027 \\
\hline & 4 & 148 & $1.6(1.08-2.36)$ & 0.018 \\
\hline \multirow[t]{4}{*}{ ALDHIBI } & I & 67 & $0.2(0.08-0.54)$ & 0.00044 \\
\hline & 2 & 140 & $0.56(0.28-1.14)$ & 0.11 \\
\hline & 3 & 305 & $0.57(0.4 \mathrm{I}-0.77)$ & 0.00029 \\
\hline & 4 & 148 & $1.96(1.2-3.19)$ & 0.0062 \\
\hline \multirow[t]{4}{*}{ ALDHILI } & 1 & 67 & $2.17(0.49-9.61)$ & 0.3 \\
\hline & 2 & 140 & $3.17(1.52-6.61)$ & 0.0012 \\
\hline & 3 & 305 & $1.79(1.24-2.56)$ & 0.0014 \\
\hline & 4 & 148 & $1.58(1.06-2.37)$ & 0.024 \\
\hline
\end{tabular}

Abbreviations: GC, gastric cancer; $\mathrm{HR}$, hazard ratio; $\mathrm{Cl}$, confidence interval.
Table 4 Correlation of ALDHI isoenzyme mRNA high expression with HER2 status of patients with GC

\begin{tabular}{|c|c|c|c|c|}
\hline Isoenzymes & HER2 status & Cases & HR $(95 \% \mathrm{Cl})$ & $P$-value \\
\hline \multirow[t]{2}{*}{ ALDHIAI } & Negative & 532 & $0.7(0.56-0.88)$ & 0.0018 \\
\hline & Positive & 344 & $0.89(0.69-1.16)$ & 0.4 \\
\hline \multirow[t]{2}{*}{ ALDHIA2 } & Negative & 532 & $1.47(1.13-1.9)$ & 0.0039 \\
\hline & Positive & 344 & $1.23(0.93-1.65)$ & 0.15 \\
\hline \multirow[t]{2}{*}{ ALDHIA3 } & Negative & 532 & $1.68(1.34-2.1 \mathrm{I})$ & $5.9 e-06$ \\
\hline & Positive & 344 & $1.6(1.23-2.07)$ & 0.00038 \\
\hline \multirow[t]{2}{*}{ ALDHIBI } & Negative & 532 & $0.8(0.64-1.0 \mathrm{I})$ & 0.064 \\
\hline & Positive & 344 & $0.58(0.44-0.76)$ & $4.6 \mathrm{e}-05$ \\
\hline \multirow[t]{2}{*}{ ALDHILI } & Negative & 532 & $1.92(I .46-2.5 \mathrm{I})$ & $1.5 \mathrm{e}-06$ \\
\hline & Positive & 344 & $1.42(1.1-1.85)$ & 0.0072 \\
\hline
\end{tabular}

Abbreviations: $\mathrm{GC}$, gastric cancer; $\mathrm{HR}$, hazard ratio; $\mathrm{Cl}$, confidence interval.

of patients with GC. In the current study, we found that mRNA high expression of ALDH1A1 was not significantly correlated with OS for all patients with GC followed for 13 years, $\mathrm{HR}=0.86$ (95\% CI: $0.7-1.05), P=0.13$. In addition, ALDH1A1 mRNA high expression was not found to be correlated with OS in intestinal-type patients, $\mathrm{HR}=0.72$ (95\% CI: $0.49-1.04), P=0.078$, and in diffuse-type patients, $\mathrm{HR}=1.52$ (95\% CI: 0.87-2.66), $P=0.13$. Similar to $A L D H 1 A 1$ mRNA, ALDH1A2 mRNA high expression was also not significantly correlated with OS for all patients with GC, HR $=1.13(95 \%$ CI: 0.91-1.41), $P=0.25$. However, $A L D H 1 A 2$ mRNA high expression was significantly correlated with better OS in diffuse-type patients, $\mathrm{HR}=0.59$ (95\% CI: 0.36-0.97), $P=0.037$. In contrast, $A L D H 1 A 3$ mRNA high expression was found to be significantly correlated with worsened OS either in intestinal-type patients, $\mathrm{HR}=2.24$ (95\% CI: 1.44-3.49), $P=0.00026$ or diffuse-type patients, $\mathrm{HR}=1.91$ (95\% CI: 1.02-3.59), $P=0.04$. Interestingly, $A L D H 1 B 1$ mRNA high expression was found to be significantly correlated with better

Table 5 Correlation of ALDHI isoenzyme mRNA high expression with different treatments of patients with GC

\begin{tabular}{|c|c|c|c|c|}
\hline Isoenzymes & Treatment & Cases & HR (95\% Cl ) & $P$-value \\
\hline \multirow[t]{3}{*}{ ALDHIAI } & Surgery alone & 380 & $0.8 \mathrm{I}(0.59-\mathrm{I} . \mathrm{II})$ & 0.19 \\
\hline & 5-FU-based adjuvant & 153 & $0.7(0.49-0.99)$ & 0.042 \\
\hline & chemotherapy & & & \\
\hline \multirow[t]{3}{*}{ ALDHIA2 } & Surgery alone & 380 & I.3। (0.97-I.77) & 0.076 \\
\hline & 5-FU-based adjuvant & 153 & $0.75(0.52-1.08)$ & 0.12 \\
\hline & chemotherapy & & & \\
\hline \multirow[t]{3}{*}{ ALDHIA3 } & Surgery alone & 380 & $2.08(1.54-2.8 I)$ & $8.9 e-07$ \\
\hline & 5-FU-based adjuvant & 153 & $0.65(0.44-0.97)$ & 0.033 \\
\hline & chemotherapy & & & \\
\hline \multirow[t]{3}{*}{ ALDHIBI } & Surgery alone & 380 & I.26 (0.93-I.7I) & 0.13 \\
\hline & 5-FU-based adjuvant & 153 & $0.56(0.39-0.81)$ & 0.0015 \\
\hline & chemotherapy & & & \\
\hline \multirow[t]{3}{*}{ ALDHILI } & Surgery alone & 380 & $1.75(1.24-2.46)$ & 0.0013 \\
\hline & 5-FU-based adjuvant & 153 & $0.77(0.54-1.1)$ & 0.15 \\
\hline & chemotherapy & & & \\
\hline
\end{tabular}
confidence interval. 
OS for all patients with GC, $\mathrm{HR}=0.66$ (95\% CI: $0.53-0.81$ ), $P=7.8 \mathrm{e}^{-}-05$, and mRNA high expression of $A L D H 1 L 1$ was found to be significantly correlated with worsened OS for all patients with GC, HR $=1.23$ (95\% CI: $1-1.51$ ), $P=0.048$. ALDH1L2 is expressed in heart, brain, liver, kidney, and pancreas using real-time polymerase chain reaction performed on an array of human tissues, but no information is available for its expression in gastric tissue. ${ }^{36}$ No survival information for ALDH1L2 in patients with GC is available, probably due to its low expression in gastric tissue and GC. We also assessed the correlation of individual ALDH1 isoenzymes' mRNA high expression with other clinicopathological features, such as pathological grades, clinical grades, HER2 status, and different choices of treatment of patients with GC. Prognostic values of the ALDH1 in several cancers have been accumulated predominantly by using immunohistochemistry of paraffin-embedded cancer tissues with isotype-specific antibodies, ALDH1A1 or ALDH1A3. ${ }^{37}$ Meta-analysis showed that ALDH1 has a poor prognosis in breast cancer, ${ }^{38,39}$ colorectal cancer, ${ }^{40}$ lung cancer, ${ }^{41,42}$ and head and neck cancer. ${ }^{43}$ In contrast to the abovementioned reports, ALDH1 is considered a marker of prediction of better prognosis in patients suffering from primary glioblastoma. ${ }^{44}$ So far, only a few studies showed the prognostic values of the mRNA expression of ALDH1 isoenzymes in patients with cancer. Liu et $a{ }^{45}$ reported that higher ALDH1A1 mRNA level was associated with improved disease-free survival ( $\mathrm{HR}=0.87$, 95\% CI: $0.80-0.95$, per log unit change) and OS (HR $=0.85$, 95\% CI: $0.78-0.93$ per log unit change) independent of age at diagnosis, TNM stage, and treatment in triple-negative breast cancer. Chen et al reveal that ALDH1L1 mRNA is significantly reduced in hepatocellular carcinoma tissues and is a new and potential prognostic marker for the survival of patients with hepatocellular carcinoma. However, the exact mechanisms of ALDH1 isoenzymes, in either protein or mRNA levels, which may affect the clinical outcome of patients with cancer are still not clear and need further study. In addition, individual ALDH1 isoenzymes may have interaction among them and finally affect the outcome of patients with GC. Unfortunately, the KM plotter is not able to analyze the correlation between the various isoforms of ALDH1. In addition, the KM plotter cannot be used to determine a positive or negative correlation between isoenzyme expressions.

ALDH1 is able to convert aldehydes into carboxylic acids in several types of normal tissues. ${ }^{46,47}$ Recently, accumulating evidence strongly indicates that ALDH1, in particular ALDH1A1, can modulate cell differentiation, proliferation, and survival, as well as the cellular response to oxidative stress in SCs. ${ }^{37}$ ALDH1 also has universal markers in CSCs including gastric CSC. However, the specific usefulness of ALDH1 in SCs and CSCs is still unclear. Currently, the activity of ALDH1 in viable cells can be determined by the use of fluorescent substrates and flow cytometry for ALDH1. 10,48,49 Katsuno et $\mathrm{a}^{50}$ isolated ALDH1+ cells from human diffusetype gastric carcinoma cells and characterized these cells using an Aldefluor assay. They found that ALDH1+ cells that constituted $5 \%-8 \%$ of the human diffuse-type GC cells were more tumurigenic than ALDH1- cells, and ALDH1+ cells were able to self-renew and generate heterogeneous cell populations. Wakamatsu et al ${ }^{12}$ immunohistochemically examined expression and distribution of ALDH1 in primary and metastatic GC and showed that the ALDH1 positivity is significantly higher in diffuse-type lymph node metastasis than in the primary tumor. Levi et $\mathrm{al}^{13}$ also observed that ALDH1 was expressed in very low levels in normal human gastric mucosa but significantly increased in gastric adenocarcinomas. Until recently, $\mathrm{Li}$ et a $\mathrm{l}^{14}$ determined that ALDH1A1 was an independent prognostic factor for both OS and RFS. However, which ones of ALDH1's isoenzymes are causing ALDH1 activity in GC and the prognostic values of most of the individual ALDH1 isoenzyme in $\mathrm{GC}$ remains elusive. Our results showed that unlike breast cancer, mRNA expression of $A L D H 1 A 1$ in $\mathrm{GC}$ is not significantly associated with OS for patients with GC. Additionally, our study results also indicate that ALDH1A3 and ALDH1L1 are potential major contributors to the ALDH1 activity in GC, since ALDH1A3 and ALDH1L1 mRNA high expression was found to be significantly correlated with worsened OS for all patients with GC. Based on our results, ALDH1 A3 and ALDH1L1 are potential excellent drug targets for patients with GC.

Previous reports have been focusing on the correlation between ALDH1A1 protein and the clinicopathologic parameters. In most types of tumors, such as, breast cancer, ${ }^{10,51,52}$ clear cell renal cell carcinoma, ${ }^{53}$ colorectal carcinoma, ${ }^{54}$ esophageal squamous cell carcinoma,${ }^{55}$ squamous cell carcinoma of the head and neck, ${ }^{56}$ and urothelial carcinomas of urinary bladder, ${ }^{57}$ ALDH1A1 protein high expression was correlated with tumor metastasis and poor prognosis. In contrast to the abovementioned studies, ALDH1A1 is also identified as a marker of astrocytic differentiation during brain development and of better prognosis in patients suffering from primary glioblastoma. ${ }^{44}$ In patients with GC who had ALDH1A1 overexpression, they also had poor OS and shorter RFS. ${ }^{14}$ In the current study, ALDH1A1 mRNA high expression was found to be correlated with worsened OS only in diffuse-type patients with GC, but not in intestinal-type patients with GC. 
The two main histologic subtypes of the disease, intestinal and diffuse type, define two distinct entities that have different etiology, pathogenesis, epidemiology, and behavior. ${ }^{58}$ In the current study, excerpt for the $A L D H 1 A 3$ mRNA high expression that was found to be correlated with worsened OS in both intestinal-type patients and diffuse-type patients, other $A L D H 1$ isoenzymes had total different OS in these two types of patients with GC. The molecular mechanisms of the regulation of $A L D H 1$ isoenzymes in intestinal and diffuse type need to be further investigated.

The HER2/neu proto-oncogene (also known as c-erbB-2) encodes for a $185 \mathrm{kDa}$ transmembrane glycoprotein receptor known as HER2/neu or p185 ${ }^{\mathrm{HER} 2}$, partial homology with epidermal growth factor receptor, shares with that receptorintrinsic tyrosine kinase activity, and has been implicated in cancer with special emphasis on breast cancer. ${ }^{59,60}$ HER2 overexpression was detected in $6 \%-35 \%$ of patients with GC and has led to the advent of targeted therapy with antiHER2 antibody such as Trastuzumab which has improved the OS. ${ }^{61,62}$ HER2 and ALDH1 have been identified as potential biomarkers of prognostic significance in patients with $\mathrm{GC} ;{ }^{63}$ however, there are no reports about the association between HER2 and ALDH1 in GC. Interestingly, there are strong evidences showing the correlation between HER2 and ALDH1 in breast cancer. ALDH1 expression was found to be correlated with HER2 overexpression $(P<0.001)$ in breast cancer. ${ }^{64}$ ALDH1+ breast cancers were also found to be associated with basal-like and HER2-overexpressing subtypes, and the characteristics histologic features were related to these two subtypes. ${ }^{65}$ In this study, we found that $A L D H 1 A 1$ and $A L D H 1 A 2$ mRNA high expression is only significantly associated with patients with HER2-negative GC. ALDH1B1 mRNA high expression is only associated with patients with HER2-positive GC. ALDH1A3 and ALDH1L1 mRNA high expression are significantly associated with patients with HER2-negative and HER2-positive GC.

In patients with breast cancer, only $A L D H 1 A 1$ mRNA high expression was found to be significantly correlated with the poor OS, indicating that $A L D H 1 A 1$ is potentially a major contributor of ALDH1 activity and a potential drug target of breast cancer. ${ }^{26}$ In contrast, in non-small-cell lung cancer, high expression of $A L D H 1 A 2$ and $A L D H 1 B 1$ mRNA was found to be significantly correlated with the poor OS in patients with non-small-cell lung cancer, indicating that ALDH1A2 and $A L D H 1 B 1$ are potential drug targets for patients with non-small-cell lung cancer. ${ }^{66}$ It is not clear about the role of each ALDH1 isoenzyme that contributes to ALDH1 activity in GC cells. It will be helpful to know which
ALDH1 isoenzyme contributes to ALDH1 activity, if we measure the changes of ALDH1 activity upon using siRNAs or antibodies of individual ALDH1 isoenzymes in GC cells. Unlike breast and non-small-cell lung cancer, only $A L D H 1 A 3$ and ALDH1L1 mRNA high expression was found to be significantly correlated with worsened OS for all patients with GC, indicating that $A L D H 1 A 3$ and ALDH1L1 might be potential drug targets for patients with GC. So far, not many specific small molecular inhibitors or other antagonists of the different ALDH1 isozymes have been developed. This lack of selectivity of available individual ALDH1 isozyme inhibitors that have been tested as anticancer agents in the clinical setting has resulted in an unacceptable side-effect profile. ${ }^{37}$ Interestingly, Condello et $\mathrm{al}^{67}$ recently developed A37 ((ethyl2-((4-oxo-3-(3-(pryrrolidin-1-yl)propyl)-3,4-dihydrobenzo [4,5]thioeno [3,2-d]pyrimidin-2-yl)thio)acetate)), a novel ALDH1A1 small-molecule enzymatic inhibitor for the first time, where it disrupted ovarian cancer cell spheroid formation and cell viability $(P<0.001)$. We expect more specific inhibitors target other ALDH1 isozymes, such as ALDH1A3 or ALDH1L1 to be developed and to be validated for their usage in the targeting CSC.

\section{Conclusion}

Using KM plotter, we identified the distinct prognostic significances of ALDH1 isoenzymes in patients with GC. Our results indicate that ALDH1A3 and ALDH1L1 are potential major contributors to the ALDH1 activity in GC, since $A L D H 1 A 3$ and ALDH1L1 mRNA high expression was found to be significantly correlated with worsened OS for all patients with GC. ALDH1A3 and ALDH1L1 are potential prognostic markers and therapeutic targets for patients with GC.

\section{Disclosure}

The authors report no conflicts of interest in this work.

\section{References}

1. Jemal A, Bray F, Center MM, Ferlay J, Ward E, Forman D. Global cancer statistics. CA Cancer J Clin. 2011;61(2):69-90.

2. Yang W, Raufi A, Klempner SJ. Targeted therapy for gastric cancer: molecular pathways and ongoing investigations. Biochim Biophys Acta. 2014;1846(1):232-237.

3. Oba K, Paoletti X, Bang YJ, et al. Role of chemotherapy for advanced/ recurrent gastric cancer: an individual-patient-data meta-analysis. Eur J Cancer. 2013;49(7):1565-1577.

4. Douville J, Beaulieu R, Balicki D. ALDH1 as a functional marker of cancer stem and progenitor cells. Stem Cells Dev. 2009;18(1):17-25.

5. Ma I, Allan AL. The role of human aldehyde dehydrogenase in normal and cancer stem cells. Stem Cell Rev. 2011;7(2):292-306.

6. Ehlers CL. Variations in ADH and ALDH in Southwest California Indians. Alcohol Res Health. 2007;30(1):14-17. 
7. Vasiliou V, Thompson DC, Smith C, Fujita M, Chen Y. Aldehyde dehydrogenases: from eye crystallins to metabolic disease and cancer stem cells. Chem Biol Interact. 2013;202(1-3):2-10.

8. Muzio G, Maggiora M, Paiuzzi E, Oraldi M, Canuto RA. Aldehyde dehydrogenases and cell proliferation. Free Radic Biol Med. 2012;52(4): 735-746.

9. Pearce DJ, Taussig D, Simpson C, et al. Characterization of cells with a high aldehyde dehydrogenase activity from cord blood and acute myeloid leukemia samples. Stem Cells. 2005;23(6):752-760.

10. Ginestier C, Hur MH, Charafe-Jauffret E, et al. ALDH1 is a marker of normal and malignant human mammary stem cells and a predictor of poor clinical outcome. Cell Stem Cell. 2007;1(5):555-567.

11. Balicki D. Moving forward in human mammary stem cell biology and breast cancer prognostication using ALDH1. Cell Stem Cell. 2007;1(5): 485-487.

12. Wakamatsu Y, Sakamoto N, Oo HZ, et al. Expression of cancer stem cell markers ALDH1, CD44 and CD133 in primary tumor and lymph node metastasis of gastric cancer. Pathol Int. 2012;62(2):112-119.

13. Levi E, Sochacki P, Khoury N, Patel BB, Majumdar AP. Cancer stem cells in Helicobacter pylori infection and aging: implications for gastric carcinogenesis. World J Gastrointest Pathophysiol. 2014;5(3): 366-372.

14. Li XS, Xu Q, Fu XY, Luo WS. ALDH1A1 overexpression is associated with the progression and prognosis in gastric cancer. BMC Cancer. 2014; $14: 705$

15. Gene Expression Omnibus [database on the Internet]. Bethesda, MD: National Center for Biotechnology Information, US Library of Medicine. Available from: http://www.ncbi.nlm.nih.gov/geo/. Accessed.

16. Gyorffy B, Lanczky A, Eklund AC, et al. An online survival analysis tool to rapidly assess the effect of 22,277 genes on breast cancer prognosis using microarray data of 1,809 patients. Breast Cancer Res Treat. 2010;123(3):725-731.

17. Gyorffy B, Benke Z, Lanczky A, et al. RecurrenceOnline: an online analysis tool to determine breast cancer recurrence and hormone receptor status using microarray data. Breast Cancer Res Treat. 2012; 132(3):1025-1034.

18. Liu M, Wang G, Gomez-Fernandez CR, Guo S. GREB1 functions as a growth promoter and is modulated by IL6/STAT3 in breast cancer. PLoS One. 2012;7(10):e46410.

19. Tilghman SL, Townley I, Zhong Q, et al. Proteomic signatures of acquired letrozole resistance in breast cancer: suppressed estrogen signaling and increased cell motility and invasiveness. Mol Cell Proteomics. 2013;12(9):2440-2455.

20. Zhou C, Zhong Q, Rhodes LV, et al. Proteomic analysis of acquired tamoxifen resistance in MCF-7 cells reveals expression signatures associated with enhanced migration. Breast Cancer Res. 2012; 14(2):R45.

21. Maciejczyk A, Szelachowska J, Czapiga B, et al. Elevated BUBR1 expression is associated with poor survival in early breast cancer patients: 15-year follow-up analysis. J Histochem Cytochem. 2013;61(5): 330-339.

22. Maciejczyk A, Lacko A, Ekiert M, et al. Elevated nuclear S100P expression is associated with poor survival in early breast cancer patients. Histol Histopathol. 2013;28(4):513-524.

23. Maciejczyk A, Jagoda E, Wysocka T, et al. ABCC2 (MRP2, cMOAT) localized in the nuclear envelope of breast carcinoma cells correlates with poor clinical outcome. Pathol Oncol Res. 2012;18(2):331-342.

24. Adam MA. New prognostic factors in breast cancer. Adv Clin Exp Med. 2013;22(1):5-15.

25. Ivanova L, Zandberga E, Silina K, et al. Prognostic relevance of carbonic anhydrase IX expression is distinct in various subtypes of breast cancer and its silencing suppresses self-renewal capacity of breast cancer cells. Cancer Chemother Pharmacol. 2015;75(2):235-246.

26. Wu S, Xue W, Huang X, et al. Distinct prognostic values of ALDH1 isoenzymes in breast cancer. Tumour Biol. 2015;36(4):2421-2426.

27. Ortega CE, Seidner Y, Dominguez I. Mining CK2 in cancer. PLoS One. 2014;9(12):e115609.
28. Gyorffy B, Surowiak P, Budczies J, Lanczky A. Online survival analysis software to assess the prognostic value of biomarkers using transcriptomic data in non-small-cell lung cancer. PLoS One. 2013;8(12): e82241.

29. Gyorffy B, Lanczky A, Szallasi Z. Implementing an online tool for genome-wide validation of survival-associated biomarkers in ovariancancer using microarray data from 1287 patients. Endocr Relat Cancer. 2012;19(2):197-208.

30. National Cancer Institute [database on the Internet]. Rockville, MD: Biorepositories and Biospecimen Research Branch, National Cancer Institute. Available from: http://biospecimens.cancer.gov/ relatedinitiatives/overview/caBig.asp. Accessed.

31. National Cancer Institute [database on the Internet]. Bethesda, MD: The Cancer Genome Atlas. National Cancer Institute. Available from: http://biospecimens.cancer.gov/relatedinitiatives/overview/caBig.asp/. Accessed.

32. Gentry T, Foster S, Winstead L, Deibert E, Fiordalisi M, Balber A. Simultaneous isolation of human BM hematopoietic, endothelial and mesenchymal progenitor cells by flow sorting based on aldehyde dehydrogenase activity: implications for cell therapy. Cytotherapy. 2007;9(3): 259-274.

33. Traore M, Zhai L, Chen M, et al. Cytotoxic kurubasch aldehyde from Trichilia emetica. Nat Prod Res. 2007;21(1):13-17.

34. Jones KM, Kitson TM, Kitson KE, Hardman MJ, Tweedie JW. Human class 1 aldehyde dehydrogenase. Expression and site-directed mutagenesis. Adv Exp Med Biol. 1995;372:17-23.

35. Levi BP, Yilmaz OH, Duester G, Morrison SJ. Aldehyde dehydrogenase 1a1 is dispensable for stem cell function in the mouse hematopoietic and nervous systems. Blood. 2009;113(8):1670-1680.

36. Krupenko NI, Dubard ME, Strickland KC, Moxley KM, Oleinik NV, Krupenko SA. ALDH1L2 is the mitochondrial homolog of 10-formyltetrahydrofolate dehydrogenase. J Biol Chem. 2010;285(30): 23056-23063.

37. Tomita H, Tanaka K, Tanaka T, Hara A. Aldehyde dehydrogenase 1A1 in stem cells and cancer. Oncotarget. 2016;7(10):11018-11032.

38. Liu Y, Lv DL, Duan JJ, et al. ALDH1A1 expression correlates with clinicopathologic features and poor prognosis of breast cancer patients: a systematic review and meta-analysis. BMC Cancer. 2014;14:444.

39. Zhou L, Jiang Y, Yan T, et al. The prognostic role of cancer stem cells in breast cancer: a meta-analysis of published literatures. Breast Cancer Res Treat. 2010;122(3):795-801.

40. Chen J, Xia Q, Jiang B, et al. Prognostic value of cancer stem cell marker ALDH1 expression in colorectal cancer: a systematic review and meta-analysis. PLoS One. 2015;10(12):e0145164.

41. Huo W, Du M, Pan X, Zhu X, Li Z. Prognostic value of ALDH1 expression in lung cancer: a meta-analysis. Int J Clin Exp Med. 2015;8(2): 2045-2051.

42. Wei D, Peng JJ, Gao H, Zhang T, Tan Y, Hu YH. ALDH1 expression and the prognosis of lung cancer: a systematic review and meta-analysis. Heart Lung Circ. 2015;24(8):780-788.

43. Zhou C, Sun B. The prognostic role of the cancer stem cell marker aldehyde dehydrogenase 1 in head and neck squamous cell carcinomas: a meta-analysis. Oral Oncol. 2014;50(12):1144-1148.

44. Adam SA, Schnell O, Poschl J, et al. ALDH1A1 is a marker of astrocytic differentiation during brain development and correlates with better survival in glioblastoma patients. Brain Pathol. 2012;22(6):788-797.

45. Liu Y, Baglia M, Zheng Y, et al. ALDH1A1 mRNA expression in association with prognosis of triple-negative breast cancer. Oncotarget. 2015;6(38):41360-41369.

46. Vasiliou V, Pappa A, Petersen DR. Role of aldehyde dehydrogenases in endogenous and xenobiotic metabolism. Chem Biol Interact. 2000; 129(1-2):1-19.

47. Vasiliou V, Nebert DW. Analysis and update of the human aldehyde dehydrogenase (ALDH) gene family. Hum Genomics. 2005;2(2):138-143.

48. Burger PE, Gupta R, Xiong X, et al. High aldehyde dehydrogenase activity: a novel functional marker of murine prostate stem/progenitor cells. Stem Cells. 2009;27(9):2220-2228. 
49. Chute JP, Muramoto GG, Whitesides J, et al. Inhibition of aldehyde dehydrogenase and retinoid signaling induces the expansion of human hematopoietic stem cells. Proc Natl Acad Sci U S A. 2006;103(31): 11707-11712.

50. Katsuno Y, Ehata S, Yashiro M, Yanagihara K, Hirakawa K, Miyazono K. Coordinated expression of REG4 and aldehyde dehydrogenase 1 regulating tumourigenic capacity of diffuse-type gastric carcinoma-initiating cells is inhibited by TGF-beta. J Pathol. 2012;228(3): 391-404.

51. Mieog JS, de KEM, Bastiaannet E, et al. Age determines the prognostic role of the cancer stem cell marker aldehyde dehydrogenase-1 in breast cancer. BMC Cancer. 2012;12:42.

52. Neumeister V, Agarwal S, Bordeaux J, Camp RL, Rimm DL. In situ identification of putative cancer stem cells by multiplexing ALDH1, CD44, and cytokeratin identifies breast cancer patients with poor prognosis. Am J Pathol. 2010;176(5):2131-2138.

53. Wang K, Chen X, Zhan Y, et al. Increased expression of ALDH1A1 protein is associated with poor prognosis in clear cell renal cell carcinoma. Med Oncol. 2013;30(2):574.

54. Xu SL, Zeng DZ, Dong WG, et al. Distinct patterns of ALDH1A1 expression predict metastasis and poor outcome of colorectal carcinoma. Int J Clin Exp Pathol. 2014;7(6):2976-2986.

55. Yang L, Ren Y, Yu X, et al. ALDH1A1 defines invasive cancer stem-like cells and predicts poor prognosis in patients with esophageal squamous cell carcinoma. Mod Pathol. 2014;27(5):775-783.

56. Xu J, Muller S, Nannapaneni S, et al. Comparison of quantum dot technology with conventional immunohistochemistry in examining aldehyde dehydrogenase 1A1 as a potential biomarker for lymph node metastasis of head and neck cancer. Eur J Cancer. 2012;48(11):1682-1691.
57. Keymoosi H, Gheytanchi E, Asgari M, Shariftabrizi A, Madjd Z. ALDH1 in combination with CD44 as putative cancer stem cell markers are correlated with poor prognosis in urothelial carcinoma of the urinary bladder. Asian Pac J Cancer Prev. 2014;15(5):2013-2020.

58. Carcas LP. Gastric cancer review. J Carcinog. 2014;13:14.

59. Tai W, Mahato R, Cheng K. The role of HER2 in cancer therapy and targeted drug delivery. J Control Release. 2010;146(3):264-275.

60. Tzahar E, Yarden Y. The ErbB-2/HER2 oncogenic receptor of adenocarcinomas: from orphanhood to multiple stromal ligands. Biochim Biophys Acta. 1998;1377(1):M25-M37.

61. Ruschoff J, Hanna W, Bilous M, et al. HER2 testing in gastric cancer: a practical approach. Mod Pathol. 2012;25(5):637-650.

62. Rajagopal I, Niveditha SR, Sahadev R, Nagappa PK, Rajendra SG. HER 2 expression in gastric and gastro-esophageal junction (GEJ) adenocarcinomas. J Clin Diagn Res. 2015;9(3):EC06-EC10.

63. Elimova E, Wadhwa R, Shiozaki H, et al. Molecular biomarkers in gastric cancer. J Natl Compr Canc Netw. 2015;13(4):e19-e29.

64. Yoshioka T, Umekita Y, Ohi Y, et al. Aldehyde dehydrogenase 1 expression is a predictor of poor prognosis in node-positive breast cancers: a long-term follow-up study. Histopathology. 2011;58(4):608-616.

65. Tsang JY, Huang YH, Luo MH, et al. Cancer stem cell markers are associated with adverse biomarker profiles and molecular subtypes of breast cancer. Breast Cancer Res Treat. 2012;136(2):407-417.

66. You Q, Guo H, Xu D. Distinct prognostic values and potential drug targets of ALDH1 isoenzymes in non-small-cell lung cancer. Drug Des Devel Ther. 2015;9:5087-5097.

67. Condello S, Morgan CA, Nagdas S, et al. beta-Catenin-regulated ALDH1A1 is a target in ovarian cancer spheroids. Oncogene. 2015; 34(18):2297-2308
OncoTargets and Therapy

\section{Publish your work in this journal}

OncoTargets and Therapy is an international, peer-reviewed, open access journal focusing on the pathological basis of all cancers, potential targets for therapy and treatment protocols employed to improve the management of cancer patients. The journal also focuses on the impact of management programs and new therapeutic agents and protocols on

\section{Dovepress}

patient perspectives such as quality of life, adherence and satisfaction The manuscript management system is completely online and includes a very quick and fair peer-review system, which is all easy to use. Visit http://www.dovepress.com/testimonials.php to read real quotes from published authors. 